\title{
IN TRUST WE THRIVE: WHAT DRIVES THE SHARING ECONOMY?
}

\author{
KINGA SZABó, DR. GAURI SHANKAR GUPTA ${ }^{l}$
}

\begin{abstract}
The rapid growth of the sharing economy in the last two decades may signal a paradigm shift in global capitalism and societal values. Digital platforms have brought together strangers with under-utilized capacities and assets with those who need them but who are not looking for ownership. The radius of trust, which was initially confined to family, friends and local communities, now encompasses strangers who speak no common language and who may live oceans apart. Trust, driven by Digital Identity (DI) and Trust and Reputation Information (TRI), has enabled what was considered improbable or even impossible some years ago. The further expansion and deepening of trust, based on new technologies combined with the international legal framework, has the potential to rewrite the apparatus of modern capitalism and societal values. Civil society and governments need to engage on this issue to guide them in a direction that is most beneficial to society. However, the current extraordinary situation due to the Coronavirus pandemic, coupled with the foreseeable tendency to complete digital control, is likely to have far-reaching impact on the future development of the sharing economy.
\end{abstract}

KEYWORDS: sharing economy, trust, digital platform, digital identity, trust and reputation information

1 Kinga Szabó is PhD Student at the SzEEDSM Doctoral Program In Business Administration Sciences at the Széchenyi István University, Győr,email: szabokinga0630@gmail.com ; Dr. Gauri Shankar Gupta is Former Ambassador of India, PhD, SzEEDSM Doctoral Program In Business Administration Sciences, of the Széchenyi István University, Győr, email: gaurishankargupta@ yahoo.co.in. 


\section{INTRODUCTION AND THEORETICAL BACKGROUND}

We humans are social animals (Aronson, 2007), driven by a need to belong (Brooks, 2011), and "an urge to merge." Therefore, sharing is as old as the very existence of mankind. In ancient times there were many examples of the sharing economy, involving hunting, fishing, farming, and cooking. Subsequently, these practices took the form of tribal or community behaviour and rules. In more recent times, public toilets, public baths, public libraries, public transport, public parks, hotels, community cooking, and similar other practices are good examples of the sharing economy. With the advent of internet, mobile devices, mobile applications, and technology platforms, the sharing economy has taken on a completely new form in the twenty-first century. Global business models have emerged driven by peer-to-peer (P2P) or consumer-to-consumer (C2C) internet platforms, social media platforms, and information systems based on real-time interaction. With the rapid growth of information technology and a variety of online platforms, the global economy has been witnessing what we call the "sharing economy" (SE), which is new form of business model for timesharing resources and assets and exchanging goods and services. This is different from opening a store, hiring employees, and selling products to consumers.

\section{DEFINING THE SHARING ECONOMY}

Bartering goods and services is an ancient practice. Before the advent of money (currency) as medium of exchange, there were physical markets for enabling the barter of goods and services. In a limited way, the modern concept of the sharing economy started with the sharing of excess- (both in terms of quantity and time) resources and assets on digital platforms. Strictly speaking, the sharing economy was initially identified with peer-to-peer platforms for time-sharing excess resources. However, over time the concept expanded and now covers some elements of e-commerce, including the bookings made through online market places. Thus, the sharing economy is an economic model based on peer-to-peer activities on an IT-based platform involving providing or sharing access to an excess of goods and services. Many academic experts describe the sharing economy as a growing ecosystem of online platforms and market places devoted to the exchange and renting of goods and services (Botsman et al. 2010; Hawlitschek et al. 2016; Lessig, 2008; Zervas et al. 2015). Traditional forms of sharing, bartering, lending, trading, renting, gifting, and swapping, are being redefined by using digital technology, which is revolutionizing and 
mainstreaming the way people consume and share knowledge (Gata, 2015).

While the term "sharing economy" is very popular and has been in use for over two decades, a widely accepted, well-articulated, precise and comprehensive definition is still lacking. Thus, multiple definitions are still under intense debate in academia, government, and the business community. The sharing economy is also known as collaborative consumption, the platform economy, access-based consumption, and so on (Botsman et al. 2010; Bardhi et al. 2012). According to Böckmann, the sharing economy refers to a business model whereby participants share unused resources and assets among them via a peer-to-peer (P2P) platform (Böckmann, 2013). This model implies the creation of economic value or the monetization of unused resources and assets through multiple transactions without loss of ownership mediated by use of a P2P platform. Thus, use of a peer-to-peer business model that provides temporary access to the private resources of other individuals using a real-time IT platform is the fundamental characteristic of the sharing economy. Economic transactions that occur in line with this model are based on payments for one-time use, or timebased rentals or fees, and do not involve the transfer of ownership. However, there are sharing economy platforms like eBay where ownership changes hands. Therefore, in this broader sense, the sharing economy implies a new economic model based on digitally-enabled, peer-to-peer platforms for goods and services that connect the spare capacity of individuals with the demand of those who need the former, and offer access by enabling renting, lending, swapping or even selling (Avital et al., 2015; Bardhi et al. 2012; Belk, 2014; Botsman et al. 2010; Möhlmann, 2015). The extensive penetration of information technology and peer-to-peer digital platforms in all spheres of human interaction has created numerous options for online communication. It has transformed the way people think, live, eat, travel, shop, entertain, and interact. On the negative side, the growth of a plethora of digital platforms over the last two decades has also given birth to an increasingly anonymous, impersonal, and virtual society that many perceive to be unpredictable, uncertain, and devoid of warmth (Cook et al., 2005; Giddens, 1990; Luhmann, 1994; Sztompka, 2000).

In most cases, these market places comprise individuals (consumers) who transact directly with other individuals (sellers), while the marketplace platform itself is maintained by a third party (Botsman et al. 2010). This new model of the economy has provided an opportunity for individual owners to use their idle assets/resources to generate regular income through use of an IT platform to generate real-time interaction. For example, Uber's platform that enables idle vehicles to be used for the transportation of passengers, and Airbnb's platform for individuals to rent unused apartments, clearly represent sources of additional income for the respective owners. Although a variety of IT platforms 
have emerged to contribute to the sharing economy, the sharing of vehicles and accommodation are two principal areas where the sharing economy has spread its wings wide and fast. The personal transportation network Uber and the accommodation-sharing platform Airbnb have emerged as global giants (Demos, 2015). The sale and exchange of goods and equipment is another important area where large platforms such as eBay have emerged.

A PwC Consumer Intelligence Series document published in 2015 estimated the size of the global sharing economy at $\$ 15$ billion, which is like to likely to expand to over $\$ 335$ billion by 2025 . According to this report, peer-to-peer access-driven business transactions are shaking up existing businesses, and 44 percent of US consumers were familiar with the sharing economy. Airbnb hosted 155 million guest stays in 2014, 22\% more than the Hilton worldwide which hosted 122 million guests. Within five years, Uber was operating in 250 cities and by February 2015 was valued at $\$ 41.2$ billion (PwC, 2015). Tech pioneers like Amazon, Google, eBay, and PayPal, coupled with smart phones, IT applications, and IT platforms have changed traditional ways of doing business within a very short span of time. Fundamental changes in social perceptions regarding the ownership of assets are one of the prime movers of the sharing economy. With such changing global perspectives, today the ownership of assets is no longer considered an important symbol of status in society. The younger generation is happy with the time-sharing of assets. According to a study conducted by Nielsen during August-September 2013 that covered 60 countries with over 30,000 respondents, sixty-eight percent of global online consumers were willing to share or rent their personal items for payment. The survey revealed that 28 percent of respondents were willing to share their electronic devices, 23 percent their power tools, 22 percent bicycles, clothing, household equipment, and sports equipment, and 21 percent their car (Nielsen, 2014). According to the Demos study, there are considerable opportunities in this booming market as there is almost $\$ 3.5$ trillion dollars' worth of resources sitting idle. These idle assets and the desire to share these assets for monetary consideration is therefore the driver of the sharing economy. Environmental considerations, a lack of space, traffic congestion, maintenance issues, and other fixed costs are other important considerations. For example, the sharing of cars reduces pollution, traffic congestion, parking problems, and fixed costs such as insurance premiums, interest on investment, and the cost of parking space. Considering the importance of the sharing economy, Rifkin described it as the third industrial revolution (Rifkin, 2011). 


\section{TRUST AS THE FOUNDATION OF THE SHARING ECONOMY}

While the factors stated above are important, trust is the cornerstone of the sharing economy. A closer look shows that trust is as old as the existence of the human race. To share is to trust. Trust is based on the strong belief that a person or institution is dependable and is going to do things in a consistent and reliable manner in accordance with assurances or expectations. This implies aligning words and action. It is improbable to conceive of the sharing of assets and resources when there is a trust deficit between the parties involved. Moreover, trust is a two-way street. Both sides must reciprocate and reinforce trust through their actions. With consistency in words and behaviour over time, trust grows and becomes firmly rooted. According to Gefen et al., "trust is the belief that the other party will behave in a dependable, ethical, and socially appropriate manner" (Gefen et al. 2003, p. 53).

Historically, trust was initially confined to family members or blood relations, which is why it is said that blood is thicker than water. Gradually, trust expanded to close friends and local communities. While there is considerable debate about the precise definition of trust, it is generally agreed that trust is a psychological state that reflects the willingness of an individual to place himself or herself in a vulnerable position vis-à-vis the actions of another individual or institution, while knowing fully well that they have no direct way of monitoring the behaviour of the other individual. Trust also depends on the place and the context. In general, trust has stronger roots in nomadic societies, tribal communities, and close-knit societies. Commenting on the historical evolution of trust, Cook and Putnam hold the view that trustworthiness and trust were initially bestowed only on members of one's family and close family friends, who formed an intimate, homogeneous community with shared norms and sets of behaviours that facilitated honesty and cooperation (Cook, 2001; Putnam, 2000). In this sense, family, neighbourhood, observed behaviour in the past, and physical proximity played an important role in fostering trust.

Sociologists believe that close social interaction helps with initiating and promoting trust. Frequent social interaction during social or religious events or community matters offers such opportunities. Linguistic affinity, ethnicity, and professional and institutional association also foster trust. Coleman argues that trust is not lodged either in the actors themselves or in the physical implements of production, but is usually built among members of closed networks, such as communities that frequently interact, and through close family, religious, and community affiliations and interactions (Coleman, 1988). According to Mayer et al. trustworthiness is the willingness to be vulnerable to the actions of another 
party, based on the expectation that the other will undertake particular action that is important to the trustor, irrespective of the ability to monitor or control that other party (Mayer et al. 1995). As suggested by Barber, trust in social exchanges is based on the expectation of the consistent fulfilment of fiduciary obligations and responsibilities based on a natural and social order. Thus, from a social perspective, trust is centred on moral duties and obligations (Barber, 1983). From a rational and financial perspective, trust centres on self-interest; an increase in trust will decrease the transaction cost associated with protecting oneself from others' opportunistic behaviour or mischief (Lauer et al. 2007). The non-fulfilment of obligations may result in substantial financial losses to the trustor.

The sharing economy represents an altogether new setting. Here, individuals are required to interact with strangers with no past experience. Moreover, unlike in a neighbourhood or in a shopping mall, interaction is not physical but mediated through an invisible platform. Additionally, such individuals may come from two different parts of the world, and may not even speak the same language. Hence, sharing goods and services via internet and digital platforms is based on the fundamental premise of de facto strangers interacting with each other in the digital virtual sphere. Most often, the role of vendor is adopted by another private individual or a corporation, such as occurs with renting out cars, two wheelers, apartments, or other equipment. Nevertheless, the platform acts as a mediator between both sides - the supply side and the demand side - of the market. Since transactions on the internet are anonymous, trust becomes a critical factor in decision making. Obviously, no-one wants to risk financial loss or the security of their person. Thus, without trust no sharing is possible, especially on a regular basis, although there may be a period of trial and error in the first few instances. Trust is central to the normal conduct and survival of any online business (Subba Rao et al. 2007), and is of the utmost importance in relation to users' intention to continue using online services (Zhou et al. 2018).

"Sharing, whether with our parents, children, siblings, life partners, friends, co-workers, or neighbours, goes hand in hand with trust and bonding" (Belk 2010, p. 717). In the context of the sharing economy, given its critical role, trust is even referred to as the currency essential for transactions to occur (Botsman et al. 2010). However, trust is a multifaceted and complex construct - often hard to pin down to one particular factor (Keen et al. 1999). Trust allows us to form communities and institutions, to cooperate and interact with each other, and even, at times, to find solutions that go beyond plain self-interest. Trust determines the nature of the relationships we form with our family and friends, and why and how we develop business relationships or decide to buy products in the marketplace (Cook et al. 2009). 
Being perceived as trustworthy is an important source of motivation that has impacts extending beyond one's immediate community circle (Sztompka, 2000). It involves the concept of reputation, which travels far and wide. A breach of trust could lead to financial loss, mental stress, and even physical harm that adversely affects reputation. For example, a defective vehicle could cause an accident, or unsafe accommodation could become the cause of illness or a source of financial loss. Therefore, given the dominance of strangers, trust in the context of the sharing economy is far more important than in an ordinary business transaction. In practice, trust starts with personal relationships, then moves to communities and functional systems and abstract social objects, and finally transcends all these circles, connecting all of them and being transformed into reputation. Thus, trust and reputation are related but not identical. Reputation is the collective opinion of a group of people regarding the performance of a platform or an entity. Reputation evolves over time. In the context of a traditional business firm or an enterprise, it is also called "goodwill." On the other hand, trust always remains the individual's subjective feeling that guides their decisions. Nevertheless, reputation is one of the most significant elements contributing to trust, and trust is the fundamental requirement for reputation. According to Fukuyama, trust and trustworthiness in the sharing economy stem from interpersonal relationships that expand outwards in a "radius of trust" (Fukuyama, 1995). That is why most empirical studies on trust have focused on reputation method.

The expansion of the sharing economy is directly correlated to the expansion of the radius of trust, particularly between strangers over digital platforms. The larger the radius of trust, the better the performance of the sharing economy. The emergence of information technologies, real-time communication networks, and rapid and innovative transport logistics have helped expand the radius of trust through effective and quick customer service without the necessity of local proximity (Mazzella et al. 2016). With new innovations, the expansion of trust has found new forms and models that transcend subjective feelings. Economies of scale, manufacturing and storage in multiple places, global financial integration, and the movement of funds and global marketing techniques have enabled corporations to develop global corporate brands with a worldwide customer base (Mazzella et al. 2016; Sundararajan, 2016). This has involved an unorthodox method of expanding trust beyond normal boundaries. Some may even describe it as substituting trust with global branding. Thus, the sharing economy seeks to mitigate "stranger-danger" bias by designing and developing new trust-building capacities among strangers who interact through digital platforms by placing people at the heart of the system. As digital technologies expand, the human and social world is undergoing a tremendous shift. The way 
we communicate and interact, and the mechanisms of conducting business and the consumption of products and services has undergone a fundamental shift. Today, not millions but billions of people connect, interact, and transact business over digital platforms based on network algorithms. Ratnasingam argues that in the context of an e-commerce environment, trust has two different forms: trust in technology and IT applications, and trust in partners (Ratnasingam, 2005). The former infuses assurances that the technological infrastructure of platforms and policies adopted by a business entity can minimize risks, whereas the latter relates to one's dispositional trust and the evaluation of one's competence, among other things (Mayer et al. 1995).

As far as the antecedents of trust are concerned, McKnight et al. classifies trustrelated issues into four categories - institutional mechanisms (institution-based trust), dispositional trust (personality-based trust), familiarity and one's first impression of another party (knowledge- and cognition-based trust), and costbenefit analysis (calculative-based trust) (McKnight et al. 1998). Institution-based trust may take the form of fair, transparent, and binding rules and regulations pertaining to a mode of transaction, for example. Indeed, when transparent rules are in place, users are likely to be more confident that the other party will behave as expected, reposing greater level of trust, assuming risks away (Gefen, 2002). Cognition-based trust is often addressed through the quality of information and privacy and protection of the security of all the users who are involved (Kim et al. 2008). Users' perceptions that the necessary security measures are in place and that sensitive information will remain protected are important for cognition-based trust. Information quality, on the other hand, relates to the accuracy and the comprehensive nature of available information, but also to the ease of locating and putting this to use (Miranda et al. 2003). Knowledge-based trust depends on perceived competence, goodwill and integrity (Lin, 2011), and brings out the importance of shared goals and understanding (Chen et al. 2014). Knowledge-based trust feeds into expectations that make it easier to associate behaviour with a likely outcome (Matzat et al. 2012). Finally, calculative trust deals with cost-benefit analysis that compares the likely costs and the expected benefits of collaboration (Gefen et al. 2003). However, this distinction is more academic. In practice, the line separating the four varieties of trust described above is very thin and very often overlapping. Individuals normally take a collective view of the impact of all the four categories when making business decisions. In this sense, trust is one single indivisible feeling that allows one to dive into the vortex of the sharing economy. 


\section{TECHNOLOGY AND TRUST}

As explained in the previous section, a solid foundation of trust is essential for economic development and the growth of markets. Both attracting investment and successfully marketing final products requires a foundation of trust. Trustbased relationships may multiply the effectiveness of an enterprise, while adversarial or antagonistic relationships could become a drain on resources (Sjoberg, 2008). Researchers and scholars from across multiple disciplines agree that trust is even more significant in relation to the growth of the sharing economy, where strangers interact and conclude business deals on IT platforms. According to Earle and Siegrist, trust is the willingness to make oneself vulnerable to another based on a judgment of similarity of intentions or values (Earle and Siegrist, 2006). Although there are no validated theories concerning the principal driver of trust in the marketplace, a literature review indicates that social capital and institutions are definitely two such drivers. Generalized trust, values, and norms of reciprocity and cooperation are viewed as the key pillars of social capital, while trust in institutions, on the other hand, is influenced by the type of institution and institutional change (Galluccio, 2018). Rothstein and Stolle promote a similar view when they say that one cannot deny that social capital is a primary driver of trust in many markets due to the personal touch and appeal it offers (Rothstein \& Stolle, 2001).

In today's world, a majority of the information and opportunities present on the local and global scene are made available to those who are connected to the channels of information or networks. The digitalization of the modern world has promoted the growth of social capital (Galluccio, 2018). Bridging social capital takes place as a result of linkages among people with different backgrounds who build networks to share their ideas, thoughts, or useful economic and social information (Nahapiet and Ghoshal, 1998). According to Kinghorn, globalization and social media have provided a platform for the formation of networks with people all around the globe, and obtaining access to privileged information through such social capital. Digital platforms such as Facebook, Twitter, Whatsapp, Instagram, and Google+, and global search engines like Google, Wikipedia, and Investopedia among others have made networking and access to information much easier by speeding up communication and permitting people to access resources that they would otherwise not have had access to (Kinghorn, 2013). Hence, in the modern era, social media represents a considerable stimulus to the radius of trust in the marketplace.

Institutions are human-made legal entities that are structured and designed for political, social, and economic interaction within society. These institutions are based on a well-structured legal framework of rules and norms. Historically, 
these institutions are known to have been created with the sole purpose of maintaining order and helping reduce uncertainty in societal interactions (Nahapiet and Ghoshal, 1998). Social capital can thrive if connected to official, political, and lawful institutions. It depends on the government, institutions, or politics to survive, and cannot operate on its own (Uzzi, 1999). State laws and rules provide support to social capital through the institutional framework by fostering trust amongst people. The cooperative ability of people is raised when supported by institutional reputation. Institutions can be built to promote the value transformation of individuals and to help generate solutions among teams that struggle with the issue of managing a shared pool of resources. A wellstructured and well-run institution is able to inspire people and give them new confidence and trust. People tend to feel appreciated when their views are taken into account positively and their complaints are acted upon (Edwards and Foley, 1998). Since trust is centred on credibility or on perceived reliability, the use of the internet and social media and other tools of modern technology by institutions could help enlarge the radius of trust. Thus, modern IT-based technology and social media have emerged as effective tools for strengthening and multiplying trust through the use of social capital and institutional frameworks.

\section{DIGITAL IDENTITY (DI) AND PUBLICITY}

Digital identity is an important innovation of the modern era that can foster trust in an unknown situation. The global reach of digital technologies and the internet have created multiple options for interaction and communication with others online. In any sharing economy transaction generally, there are three factors; person, product, and platform (the three Ps). Of course, the person is the most significant of the three, as individuals are the decisionmakers and must accept the related consequences of their decisions. However, the platform that offers a product or service, and the products and services themselves, are equally important. The digital identity of an entity or a platform or an individual is the "overall online footprint over a period of time." Online reviews are considered an important form of computer-mediated communication. Such DI emerges after a reasonable period of time based on the interplay of information and evaluation willingly shared by the users of the sharing economy platform based on their past experiences. Online reviews can be used as an information source about prior consumer experiences, and for disentangling the different service features that impact user perceptions (Siering et al. 2018). Moreover, online reviews tend to be seen as more useful than more standardised information (such as security 
assurances and certifications), especially because they communicate the actual experiences of others (Cheng et al. 2019). Text-based feedback is becoming even more popular as it contains rich qualitative information about perceptions, preferences, and behaviour, with research showing that online reviews exert significant influence on other users' buying choices (Matzat et al. 2012). While in general digital identity is a complex and multifaceted concept, in the context of the sharing economy it acquires new significance and a more precise meaning. This arises from the interplay of the information willingly shared by the users of digital platforms about their peers regarding their past interactions with them, as well as about the performance of platforms themselves. Such reputationbuilding information constitutes the core of any sharing economy platform.

User Generated Content (UGC) is converted through statistical synthesis into a Reputation Score. Such reputation scores are also knowns as Trust and Reputation Information (TRI). Most sharing economy platforms actively promote mechanisms through which users can share their reviews and rate others. Such reviews and ratings are normally sought out using a scale of 1-5, or 1-10, supplemented with additional questions and comments. Such online reviews have become standard practice in the sharing economy sector. Very often, reputation scores are prominently displayed on the platform. For example, Uber asks both drivers and passengers to review their trips. In addition to the overall review, passengers are also asked questions about punctuality, the behaviour of the driver, the cleanliness of the car, and so on. Similar review statements are encouraged by Airbnb and Booking.com and most other platforms. Based on this UGC, the reputation score of each driver and each unit of accommodation is calculated and displayed on the platform, which helps with building trust and guiding the behaviour of the consumer. Simultaneously, drivers are rewarded based on their passenger reviews.

In the case of car sharing for long-distance travel between two cities and accommodation, such reviews are even more significant. No one wants to undertake long-distance travel in a car with an unreliable driver, or stay in accommodation that is unsafe or unhygienic. Precisely for this reason, customer reviews serve as the most significant factor in car-sharing decisions related to long-distance routes, as in the case of Oszkár in Hungary. Similarly, in the case of Airbnb, occupants provide their reviews about the quality of accommodation and services offered, which serve as the basis for decisions by future clients. In practice, such reviews play a significant role in the trust awarded individuals in favour of or against a particular service. While trust is an important factor in any business transaction, the presence of trust is a major precondition for successful transactions in the sharing economy. Trust helps to alleviate uncertainty in a complex and unknown business environment that may be associated with 
financial and security-related risk.

Internet users interact with multiple sources before they firm up their decisions. Many platforms offer a comparative list of prices to prospective buyers. Price, service, and trust are then woven into one package before the order is placed. Therefore, the buyer's expectation that the behaviour of the other party in the transaction will not deviate from the stated agreement is extremely important. Similarly, the party that offers the service on the platform expects the other party to use resources as per the conditions of the contract. Hence, the notion of platform-mediated, peer-to-peer trust has important implications for the sharing economy. Its multi-entry characteristics involve peers on both the supply and demand side, as well as platform providers. These enlarged human circles empowered by new trust-building digital mechanisms have made "stranger sharing" a growing reality in the modern era. The increasing number of IT platforms, and their success, are good indicators that digitally generated Trust Reputation Information has been successful in fostering consumer confidence and trust. Perhaps without designing for digital trust, the sharing economy might never have emerged the way it did. Today, DI and TRI have become an integral part of publicity, not only in the case of the sharing economy platforms, but for the entire range of e-Commerce.

\section{TRUST AND LEGAL FRAMEWORK}

The legal framework governing economic transactions is an important element in the promotion of trust. In the traditional economy, transactions are protected through a variety of national and international laws, regulations, and business practices. For example, hotels, taxis, and restaurants are strictly regulated by local laws concerning, pricing, hygiene, quality, security, and so on. If the requisite standards are lacking, customers are duly compensated. However, in the sharing economy an adequate legal framework for consumer protection is still missing, partly due to the evolving nature of this sector, and partly due to the very special operating features and the parameters of the sharing economy. There is a view that any elaborate legal measures governing this segment of the economy have the potential to become very intrusive, impinging on the privacy of individuals. For example, generating a legal framework for governing the millions of individual drivers operating for Uber is not an easy process. It is precisely for this reason that some Uber drivers have been found to be involved in cases of misbehaviour, theft and even rape. Similarly, in some cases accommodation provided through the Airbnb platform 
has been found to be unsafe and unsuitable for habitation. In the absence of specific laws governing the sharing economy, all such cases are dealt with under the normal civil and criminal laws of the respective country. Therefore, in the absence of a comprehensive legal framework, the trust factor acquires added importance. The sharing economy has four drivers; social, economic, environmental, and practical (Lea, 2015). However, no matter which motive lies behind sharing, trust is the key to sustaining the sharing economy's growth and success (Botsman et al. 2010).

Since IT platforms facilitate all peer-to-peer transactions and interactions that take place through their digital channels, the adequate monitoring of such platforms is also needed. To enforce such monitoring at a global level, an internationally accepted legal framework, guidelines, and norms are needed to prevent misuse and manipulation of the vast amount of information that is generated (Sztompka, 2000). Such legal measures would help enlarge the radius of trust that is so critical for the continued growth and success of the sharing economy. Since social evolution gives birth to legal frameworks, new laws governing the sharing economy will emerge in the years ahead. Intense debate is already underway about this issue.

\section{THE WAY FORWARD}

The sharing economy is a new disruptive paradigm that has the potential to rewrite the social and economic model of world capitalism. Being successful in the sharing economy means building business models that are based on trust, authenticity, and transparency with customers. Trust is the cornerstone of the sharing economy. With new advances in IT technology, user-generated digital information has further expanded the narrow base of trust which was initially confined to family, friends, and local community. The risk of allowing strangers into one's private space is not an easy barrier to overcome. IT platforms and TRI have made it possible. As of now, global sharing firms are in the lead with regard to transforming business ethics, economic practices, societal norms, and legal and moral codes of conduct. They are engaged in rewriting consumer behaviour and business practices. In a deeper sense, sharing economy actors have initiated a societal shift through facilitating trust between strangers. The application of business practices in the sharing economy could be improved further based on the analysis and experiences of platforms in local, regional, national, and international settings. Legislative measures and business guidelines based on best practices could further enhance the radius of trust. In this context, the 
engagement of civil society and governments is indispensable for reshaping globalized society and business practices. The further enrichment and expansion of digital platforms' feedback mechanisms are important for expanding and deepening trust.

While User Generated Content on platforms is relatively widespread these days, in the future digital trust could be accumulated in the form of trust capital which could be utilized and exported, not just on a single platform, but across a plethora of platforms and applications, similar to the notion of digital social capital that allows users to display Facebook friends or LinkedIn contacts exported from other digital networks. Such trust capital could be collected through the different interactions of individuals on social media, digital platforms, and other virtual fora such as banks, insurance companies, legal firms, and supermarkets. Although this could immensely enrich digital TRI, such a possibility will have to address privacy issues satisfactorily before it could be put into practice, as sensitive information about individuals is also prone to risks regarding cyber security, data exploitation, and surveillance issues. Moreover, the question of statistical uniformity is also important, since at times collecting and collating information from different digital settings and entities could also lead to confusion and contradictions as all these entities may operate in line with different parameters with different objectives. However, rapid advances in blockchain technology have the potential to facilitate direct peer-to-peer interaction in the sharing economy (Sundararajan, 2016). Building trust among strangers is indeed a spectacular achievement of the sharing economy model, particularly when person-to-person direct interaction was on the decline in the recent past. Of course, further debate involving all stakeholders is needed about this extremely important and sensitive issue before digital trust can transform our stranger-danger mentality into the perception that "strangers=friends." New national and international legal frameworks could be needed to address some of the fears and legal issues. These economic platforms have penetrated the lives of individuals and society as a whole using the very data provided by the individuals who use these platforms. This penetration has the capacity to bring about a radical shift in human society and the global economy.

Before we conclude, a preliminary assessment of the impact of the Coronavirus which has turned the world upside down would be desirable. The global economy and human activities came to a complete halt during March-June, 2020, as never seen before. Most of the global population were confined to their homes. The incalculable human and economic toll exacted by the rapid spread of the killer virus that originated in Wuhan, China has shaken up the global economy and geopolitics. Since mid-June, economies and human lives have started being unlocked in phases, although the restoration of the former status quo is still far 
away. The unlocking of economies and human lives has also led to spikes in the spread of Coronavirus in some countries/regions, creating new uncertainties. These uncertainties are likely to continue until an effective vaccine against Coronavirus is available. By most accounts, this may take another three to six months. According to Worldometers, as of July 5, 2020, there were 11.4 million cases of infection and a total of 5,34,164 deaths, with the USA, Brazil, Russia, and India having the most infected (Worldometers, July 5, 2020). Keeping these limitations in mind, the following predictions have been made by the UN, IMF, and other global institutions about the potential economic impact in the near future.

The UN Department of Economic and Social Affairs (DESA) has predicted serious disruption in global supply chains and international trade, with nearly 100 countries closing national borders during the past months due to the Coronavirus pandemic. DESA has observed that the movement of people and tourism flows have come to a screeching halt. With the large-scale restrictions on economic activities and heightened uncertainties, the global economy has come to a virtual standstill in the second quarter of 2020. "We are now facing the grim reality of a severe recession of a magnitude not seen since the Great Depression" stated DESA (UN News, May 13, 2020). In the same message, UN DESA predicted that the world economy would shrink by $3.2 \%$; the economies of the developed countries would contract by $5 \%$; and those of developing countries by $0.7 \%$ during 2020 . According to the International Monetary Fund (IMF), the world economy will contract by $4.9 \%$ in $2020,1.9$ percentage points less than the April 2020 World Economic Outlook (WEO) forecast of the IMF. The IMF confirms that the COVID-19 pandemic has had a more negative impact on activity in the first half of 2020 than anticipated, and that recovery is projected to be more gradual than previously forecast. In order to ensure a smooth recovery, the IMF has recommended strong multilateral cooperation on multiple fronts, liquidity assistance for countries confronting health crises, and debt relief and financing through the global financial safety net (IMF, World Economic Outlook, June 2020). Statista admits that while there is no way to tell exactly what the economic damage from the global coronavirus pandemic will be, there is widespread agreement among economists that it will have severe negative impacts on the global economy. Early estimates predicated that most major economies will lose at least 2.4 percent of the value of their gross domestic product (GDP) in 2020 (Statista, June 2020).

Based on the above, it is clear that the global economy will contract somewhere between 3 and 5\% in 2020. The re-opening of borders will take time due to fears of a revival of the pandemic adversely affecting the travel and tourism 
industry. This would naturally have negative impacts on the sharing economy, which could be somewhat greater than the general economic decline. Uber has already closed down some of its offices abroad due to a lack of business. Airbnb has done so as well. This pandemic is a defining moment that could reshape the global economy and human society and the way we interact, socialize, eat, travel, shop, entertain and live. However, it is premature to objectively evaluate the precise impact of this pandemic on the sharing economy at this moment. Moreover, this is the subject matter for another article.

\section{REFERENCES}

Aronson, Elliot (2007) The Social Animal. Palgrave Macmillan, 10th revised edition,

Avital, Michael- Carroll, M. John- Hjalmarsson, Anders- Levina, NataliaMalhotra, Arvind-Sundararajan, Arun (2015) The Sharing Economy: Friend or foe? Paper presented at the 36th International Conference on Information Systems, Fort Worth, TX.

Barber, Bernard (1983) The Logic and Limits of Trust, New Brunswick, N.J.: Rutgers University Press

Bardhi, Fleura- Eckhardt, M. Giana (2012) Access-based Consumption: the case of car sharing. Journal of Consumer Research, Vol. 39, No. 4S., pp. 881-898, DOI: https://doi.org/10.1177/1470593119856650

Belk, Russell (2010) Sharing. Journal of Consumer Research, Vol. 36, No. 5S., pp. 715-734, DOI: https://doi.org/10.1086/612649

Belk, Russell (2014) You are what you can access: Sharing and collaborative consumption online. Journal of Business Research, Vol. 67, No. 8S., pp. 15952000, DOI: https://doi.org/10.1016/j.jbusres.2013.10.001

Böckmann, Marco (2013) The sharing economy: It is time to start caring about sharing; value creating factors in the sharing economy, 1st IBA Bachelor Thesis Conference, June 27th, 2013, Enschede, The Netherlands.

Botsman, Rachel-Rogers, Roo (2010) What's Mine is Yours: The Rise of Collaborative Consumption, New York, NY: Harper Collins.

Brooks, David (2011) The Social Animal: The Hidden Sources of Love, Character, and Achievement, Random House

Coleman, James. S. (1988) Social Capital in the Creation of Human Capital. American Journal of Sociology, Vol. 94, pp. 95-120,

Cheng, Xusen- Fu, Shixuan- Sun, Jianshan- Bilgihan, Anil- Okumus, Fevzi (2019) An investigation on online reviews in sharing economy driven 
hospitality platforms: A viewpoint of trust. Tourism Management, Vol. 71, pp. 366-377, DOI: 10.1016/j.tourman.2018.10.020

Cook, Karen S. (2001) Trust in Society. New York, NY: Russell Sage Foundation Cook, Karen S.- Levi, Margaret- Hardin, Russell (2009) Whom Can We Trust? How Groups, Networks and Institutions Make Trust Possible, New York, NY: Russell Sage Foundation

Cook, Karen S.-Hardin, Russell- Levi, Margaret (2005) Cooperation Without Trust?, New York, NY: Russell Sage Foundation

Chen, Ying-Hueih- Lin, Tzu-Pei- Yen, David C. (2014) How to facilitate interorganizational knowledge sharing: The impact of trust. Information \& Management, Vol. 51, No. 5, pp. 568-578, DOI: 10.1016/j.im.2014.03.007

Demos, Telis- MacMillan, Douglas (2015) Uber Valued at More Than $\$ 50$ Billion. http://www.wsj.com/articles/uber-valued-at-more-than-50-billion-1438367457 Last access: 30032020

Earle, Timothy E. - Siegrist, Michael (2006) Morality information, performance information, and the distinction between trust and confidence. Journal of Applied Social Psychology Vol. 36, No. 2S., pp. 383-416, DOI: 10.1111/j.00219029.2006.00012

Edwards, Bob- Foley, Michael W. (1998) Civil Society and Social Capital beyond Putnam. American Behavioral Scientist, Vol. 42, No. 1S., pp. 124-139, DOI: $10.1177 / 0002764298042001010$

Fukuyama, Francis (1995) Trust: The Social Virtues and the Creation of Prosperity, New York, NY: Free Press.

Galluccio, Caterina (2018) Trust in the Market: Institutions versus Social Capital. Open Journal of Political Science, Vol. 8, No. 2S., pp. 95-107, DOI: 10.4236/ojps.2018.82008

Gata, João E. (2015) The Sharing Economy, Competition and Regulation, CPI. Gefen, David (2002) Customer loyalty in e-commerce. Journal of the Association for Information Systems, Vol. 3, No. 1S., pp. 27-51, DOI: 10.17705/1jais.00022 Gefen, David- Karahanna, Elena- Straub, Detmar W. (2003) Trust and TAM in Online Shopping: An Integrated Model. MIS Quarterly, Vol. 27, No. 1S., pp. 51-90, DOI: 10.2307/30036519

Giddens, Anthony (1990) The Consequences of Modernity, Cambridge: Polity Press.

Hawlitschek, Florian- Teubner, Timm- Adam, Marc T.P.- Borchers, Nils S.- Möhlmann, Mareike- Weinhardt, Christof (2016) Trust in the sharing economy: an experimental framework. Thirty Seventh International Conference on Information Systems (ICIS 2016). Proceedings of the Thirty Seventh International Conference on Information Systems (ICIS 2016) (Dublin, Ireland 11-14 December, 2016) pp. 1-14 
IMF, World Economic Outlook, (June 2020) A Crisis Like No Other, An Uncertain Recovery. https://www.imf.org/en/Publications/WEO/Issues/2020/06/24/ WEOUpdateJune2020 Last access: 04072020

Kinghorn, Jordan (2013). The Internet: An Investigation into the Contemporary

Sources of Social Capital. Sigma: Journal of Political and International Studies, Vol. 30, No. 5S., pp. 38-55,

Keen, Peter- Balance, Craigg- Chan, Sally- Schrump, Steve (1999) Electronic Commerce Relationships: Trust by Design. Prentice Hall PTR, Upper Saddle River

Kim, Dan J.- Ferrin, Donald L. - Rao, H. Raghav (2008) A trust-based consumer decision-making model in electronic commerce: The role of trust, perceived risk, and their antecedents. Decision Support Systems, Vol. 44 No. 2, pp. 544-564, DOI: https://doi.org/10.1016/j.dss.2007.07.001

Lea, Rude (2015) Four Keys to a Successful Sharing Economy Business Model https://www.text100.com/articles/technology/sucessful-sharing-economybusiness-model/ Last access: 30032020

Lauer, Thomas - Deng, Xiaodong (2007) Building on line trust through privacy practices. International Journal of Information Security Vol. 6, No.5S., pp. 323-331, DOI:10.1007/s10207-007-0028-8

Lessig L. Remix (2008) Making art and commerce thrive in the hybrid economy. Penguin

Lin, Hsiu-Fen (2011) An empirical investigation of mobile banking adoption: The effect of innovation attributes and knowledge-based trust. International Journal of Information Management, Vol. 31, No. 3, pp. 252-260. DOI: 10.1016/j.jiinfomgt.2010.07.006

Luhmann, Niklas (1994) Risk: A Sociological Theory, New York, NY: Aldine de Gruyter

Mayer, Roger C.- Davis, James H.- Schoorman, David F. (1995) An Integrative Model of Organizational Trust. Academy of Management Review, Vol. 20, No. 3S., pp. 709-734, DOI:10.2307/258792

Matzat, Uwe- Snijders, Chris (2012), Rebuilding Trust in Online Shops on Consumer Review Sites: Sellers' Responses to User-Generated Complaints. Journal of Computer-Mediated Communication, Vol. 18, No. 1S., pp. 62-79, DOI: 10.1111/j.1083-6101.2012.01594.x

Mazzella, Frédéric- Sundararajan, Arun- D’Espous, Verena- Möhlmann, Mareike (2016) How Digital Trust Powers the Sharing Economy. IESE Insight, No. 30, Third Quarter., pp. 24-31. DOI: 10.15581/002.ART-2887

McKnight, D. Harrison- Cummings, L. Larry- Chervany, Norman L. (1998), Initial Trust Formation in New Organizational Relationships, The Academy of Management Review, Vol. 23, No. 3, pp. 473-490. DOI: 10.2307/259290 
Miranda, Shaila M- Saunders, Carol S. (2003), The Social Construction of Meaning: An Alternative Perspective on Information Sharing, Information Systems Research, Vol. 14, No. 1S., pp. 87-106., DOI: 10.1287/ isre.14.1.87.14765

Möhlmann, Mareike (2015) Collaborative consumption: Determinants of satisfaction and the likelihood of using a sharing economy option again. Journal of Consumer Behaviour, Vol. 14, No. 3., pp. 193-207, DOI: 10.1002/ cb. 1512

Nahapiet, Janine- Ghoshal, Sumantra (1998) Social Capital, Intellectual Capital, and the Organizational Advantage. Academy of Management Review, Vol. 23, No. 2S., pp. 242-266, DOI: 10.2307/259373

Nielson, (2014) Is Sharing the New Buying? https:/www.nielsen.com/in/en/ insights/report/2014/is-sharing-the-new-buying Last access 30032020

Putnam, Robert D. (2000) Bowling alone: America's declining social capital. In: Lane Crothers- Charles Lockhart (eds), Culture and Politics. New York, NY: Palgrave Macmillan, pp. 223-234.

Pwc.com, (2015) The Sharing Economy, Consumer Intelligence Series. https://www.pwc.com/us/en/technology/publications/assets/pwc-consumerintelligence-series-the- sharing-economy.pdf Last access 30032020

Ratnasingam, Pauline (2005) Trust in inter-organizational exchanges: a case study in business to business electronic commerce. Decision Support Systems, Vol. 39, No. 3, pp. 525-544, DOI: 10.1016/j.dss.2003.12.005

Rifkin, Jeremy (2011) The Third Industrial Revolution, Palgrave MacMillan.

Rothstein, Bo- Stolle, Dietlind (2001) Social Capital and Street-Level Bureaucracy: An Institutional Theory of Generalized Trust. In ESF Conference Social Capital: Interdisciplinary Perspectives (pp. 71-83). United Kingdom: Exeter.

Siering, Michael- Deokar, Amit V.- Janze, Christian (2018) Disentangling consumer recommendations: Explaining and predicting airline recommendations based on online reviews. Decision Support Systems, Vol. 107, pp. 52-63. DOI: 10.1016/j.dss.2018.01.002

Sjoberg Lennart (2008) Antagonism, Trust and Perceived Risk. Risk Management, Vol. 10, pp. 32-55, DOI: 10.1057/palgrave.rm.8250039

Statista, (June 26, 2020) Impact of the coronavirus pandemic on the global economy - Statistics \& Facts. Online. https:/www.statista.com/topics/6139/ covid-19-impact-on-the-global-economy/ Last access 05072020

Subba Rao, S.- Truong, Dothang- Senecal, Sylvain- Le, Thoung T. (2007) How buyers' expected benefits, perceived risks, and e-business readiness influence their e-marketplace usage. Industrial Marketing Management, Vol. 36, No. 8S, pp. 1035-1045, DOI: 10.1016/j.indmarman.2006.08.001 
Sundararajan, Arun (2016) The Sharing Economy: The End of Employment and the Rise of Crowd-Based Capitalism, Cambridge, MA: MIT Press

Sztompka, Piotr (2000) Trust: A Sociological Theory, Cambridge: Cambridge University Press

UN News, (May 13, 2020) Coronavirus 'grim reality': World economy to shrink by 3.2 per cent, new UN report project. https://news.un.org/en/ story/2020/05/1064032 Last access: 02072020

Uzzi, Brian (1999). Embeddedness in the Making of Financial Capital: How Social Relations and Networks Benefit Firms Seeking Financing. American Sociological Review, Vol. 64, No. 4S., pp. 481-505, DOI: 10.2307/2657252

Worldometers, Coronavirus Cases (July 5, 2020) https://www.worldometers. info/coronavirus/ Last access 05072020

Zervas Georgios- Proserpio Davide- Byers John (2015) A first look at online reputation on Airbnb, where every stay is above average. https://ssrn.com/ abstract $=2554500$ Last access 03302020

Zhou, Wangyue- Tsiga, Zayyad- Li, Byoing Zheng, Shuning- Jiang, Shuli (2018), What influence users' e-finance continuance intention? The moderating role of trust, Industrial Management \& Data Systems, Vol. 118 No. 8, pp. 16471670, DOI: 10.1108/IMDS-12-2017-0602 